\title{
Metastasis in the wild: investigating metastasis in non-laboratory animals
}

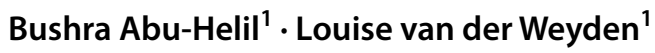

Received: 11 December 2018 / Accepted: 29 January 2019 / Published online: 9 February 2019

(c) The Author(s) 2019

\begin{abstract}
Humans are not the only species to spontaneously develop metastatic cancer as cases of metastasis have been reported in a wide range of animals, including dinosaurs. Mouse models have been an invaluable tool in experimental and clinical metastasis research, with the use of genetically-engineered mouse models that spontaneously develop metastasis or ectopic/ orthotopic transplantation of tumour cells to wildtype or immunodeficient mice being responsible for many key advances in our understanding of metastasis. However, are there other species that can also be relevant models? Similarities to humans in terms of environmental exposures, life-span, genetics, histopathology and available therapeutics are all factors that can be considered when looking at species other than the laboratory mouse. This review will explore the occurrence of metastasis in multiple species from a variety of domestic, captive and free-living veterinary cases to assist in identifying potential alternative experimental and clinical research models relevant to humans.
\end{abstract}

Keywords Metastasis · Cancer · Animal model $\cdot$ Veterinary $\cdot$ Domestic $\cdot$ Free-living $\cdot$ Comparative oncology

\section{Introduction}

Metastasis continues to be the main cause of mortality in human cancers. Despite infrequent development of spontaneous tumours in wild rodent populations [1], mice are the most commonly used model in cancer research and continue to be effective, however are limited in recapitulating the complexity of the metastatic cascade, with a $<8 \%$ successful translation rate from animal models to clinical cancer trials [2]. Utilising the spontaneously occurring instances of metastasis outside of inbred controlled laboratory populations may be the way to obtain more relevant and faithful models. Recent advancements in the detection, treatment and monitoring of cancer progression has contributed to an increase of veterinary pathology cases reporting metastasis. In addition, veterinarians find that for companion animals, there is generally a very high rate of compliance with treatment and re-check visits, and an 80-90\% rate of necropsy (autopsy) [3]. Confirmation of malignancy in domestic

Bushra Abu-Helil

ba9@sanger.ac.uk

1 Experimental Cancer Genetics (T113), Wellcome Sanger Institute, Wellcome Genome Campus, Hinxton, Cambridge CB10 1SA, UK animals is via histological examination, and the World Health Organisation's (WHO) grading and TNM staging system specifically for domestic animals continues to be commonly used in veterinary reports to characterise disease progression in an internationally recognised and standardised manner [4]. In many of these cases, cytokeratin markers and altered protein expression levels are used to differentiate metastatic nodules, analogous to that performed in the diagnosis of metastasis in human patients [5, 6]. Domestic, in particular companion animals, are susceptible to disease states present in some humans (such as obesity, diabetes, stress), and exposed to similar environmental factors that humans encounter (such as pollution, second-hand smoke), thus they represent relevant models to investigate the roles these parameters play in both the development of metastasis and efficacy of its treatment. Even in non-domestic species there are detailed veterinary reports of metastasis occurrences in a wide range of animals. The use of non-domestic species affords the opportunity to study the natural history of metastasis development without the confounding effects of therapy, which is rarely achievable in human studies. Thus, there is much we could learn about metastasis from broadening our focus of experimental models beyond laboratorybred animals. 


\section{Occurrences of spontaneous metastasis in non-laboratory animals}

Whilst it is not surprising that metastasis would occur in non-laboratory animals belonging to the Mammalia class (examples listed in Table 1), extensive searching of the literature has shown evidence of spontaneous metastases in an amazingly wide range of non-mammalian species. For example, marine bivalves, such as the softshell clam (Mya arenaria) can develop germinomas (gonadal neoplasms) that are capable of metastasizing. In a study of softshell clams from Long Cove in Maine between 1971 and 1975 , up to $22 \%$ of individuals examined had neoplasms and metastasis was noted in $40 \%$ of these cases [7]. Twelve fully grown pike (Esox lucius) kept in a tank at the New York Aquarium all died at various intervals between 1940 and 1941 and autopsies showed massive growths in the kidneys (histopathologically diagnosed as lymphosarcomas), with metastasis to the spleen and liver [8]. A retrospective survey of neoplasia in Philadelphia Zoo from 1901 to 2002 revealed 5/19 (25\%) of the neoplasms found in lizards and 6/58 (9\%) of the neoplasms found in snakes, all of which were carcinomas, showed evidence of metastasis (primarily to the liver, but also the pancreas, lung, spleen, and mesentery) [9]. Metastatic squamous cell carcinoma spreading to the liver, lung and/or kidneys has been described in case reports of two stranded loggerhead sea turtles (Caretta caretta) [10] and a wild-caught saltwater crocodile (Crocodylus porosus) [11]. There is a case report of a cockatiel (Nymphicus hollandicus) with a seminoma that had metastasized to the liver [12]. Even a section of Allosaurus humerous from the Upper Jurassic Morrison Formation (collected in Colorado) showed evidence of the presence of metastatic cancer [13]. Additional examples of non-mammalian species with reports of metastatic cancer are listed in Table 2.

However, whilst reports of metastases in animal species outside the laboratory is of great interest, an argument for the use of these animals as alternatives for experimental and clinical modelling of metastasis is only possible if their disease faithfully recapitulates the genetics, pathology and drug responses of that seen in humans. Despite the enormous range of species within the Mammalia class alone, there are many examples of striking similarities between metastasis in humans and other vertebrates. For example, embryonal rhabdomyosarcoma (ERMS) is the most common soft tissue sarcoma occurring in children. Typically occurring in the head and neck, ERMS is treated with surgical excision and adjuvant chemo- or radiation therapy, however survival of patients rapidly decreases with development of metastasis [54]. Mirroring this is a case report of a juvenile captive Rothschild's giraffe with ERMS that was treated with surgical resection and 5-fluorouracil, however, it died shortly after due to the invasiveness of the disease and at time of necropsy there was evidence of metastatic spread to the sinuses, lymph nodes and lung [29]. Similarly, there is a case report of a 2 year old golden retriever with ERMS (in which diagnosis was confirmed by positive immunohistochemical staining for desmin, also used for diagnostic testing of ERMS in human patients) with metastatic spread to the lymph nodes and lungs, and despite three doses of radiation therapy and chemotherapy (vincristine, cyclophosphamide, and doxorubicin) it was eventually euthanized due to widespread metastatic disease [55]. Below we highlight further examples of similarities in the aetiology, histopathology, genetics and response to therapy of metastasis in non-laboratory bred mammals.

\section{Aetiological similarities}

Breast cancer is the most common invasive cancer in women. The aetiology of invasive breast cancer in humans has been linked to a variety of causes, many of which are mirrored in the spontaneous development of aggressive mammary cancer (with metastasis) in animals. For example, epidemiological and experimental evidence implicates oestrogen exposure in the aetiology of breast cancer in humans (either from endogenous sources, hormone treatments or exposure environmental xenoestrogens (organochlorines)) [56] and is also considered a major factor in the development of aggressive mammary adenocarcinomas (including reports of metastasis) in the St. Laurence Estuary Beluga whale (Delphinapterus leucas) population [30]. The role of hormonal influence in the initiation and progression of breast cancer has also been recognised in canines [57]. Obesity increases the risk of breast cancer in post-menopausal women and is associated with a poor prognosis [58]. A study investigating the features of canine mammary carcinomas according to body score found a lower age of onset and more frequent lymphatic invasion of carcinoma cells in overweight or obese dogs compared with lean or ideal bodyweight dogs [59]. Obese women have been shown to have lower plasma adiponectin levels compared with non-obese women [60], and reduced adiponectin expression has been reported in mammary carcinomas from overweight or obese female dogs, with lymphatic invasion levels being lower in adiponectin-positive mammary carcinomas [59].

Approximately a fifth of all human cancers worldwide are caused by infectious agents; some examples of viruses causally linked to the aetiology of cancers include human papilloma virus in cervical cancer, hepatitis B virus in hepatocellular carcinoma, and herpesvirus [Epstein-Barr virus (human herpesvirus 4) and Kaposi's sarcoma herpesvirus (human herpesvirus 8)] in Burkitt's lymphoma and 


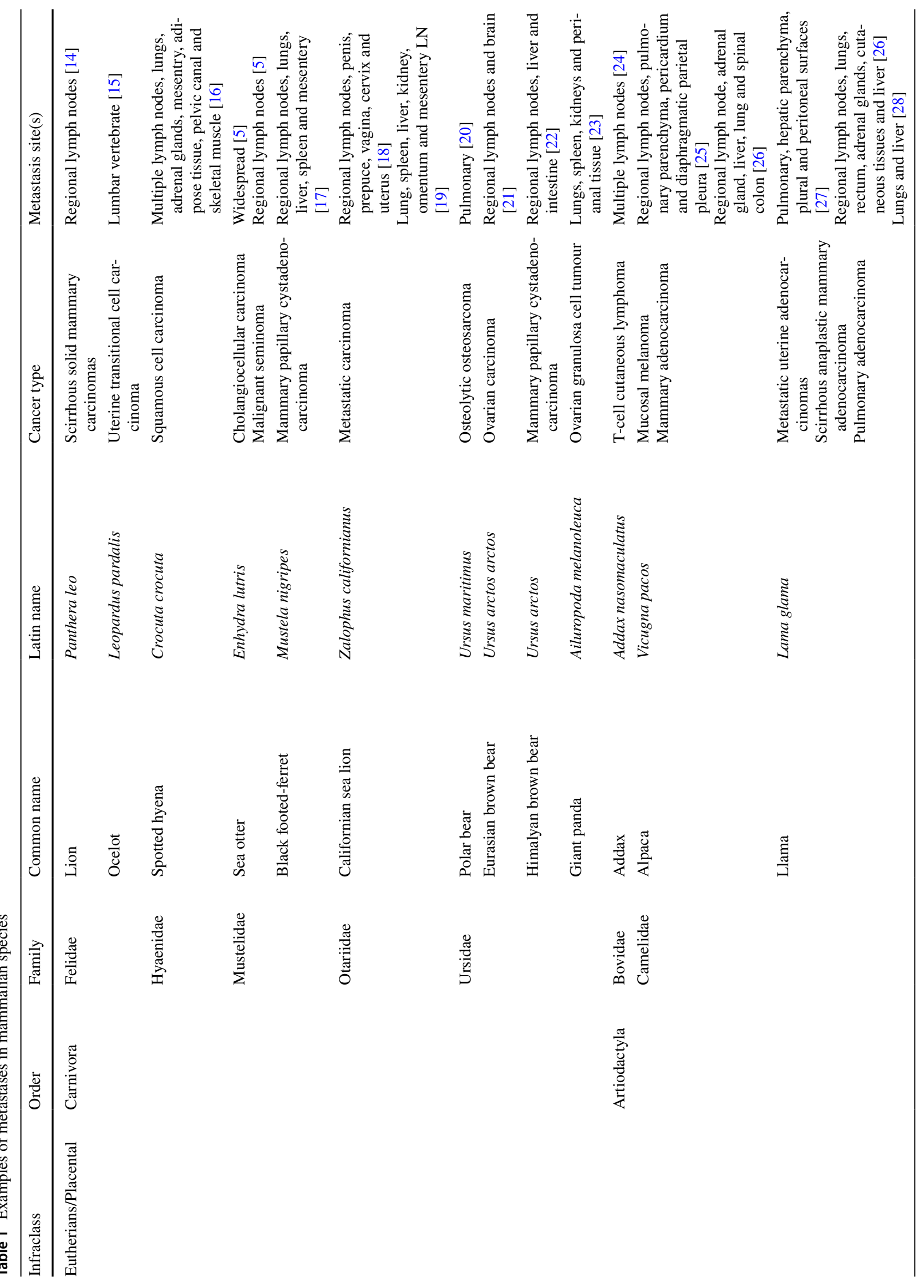




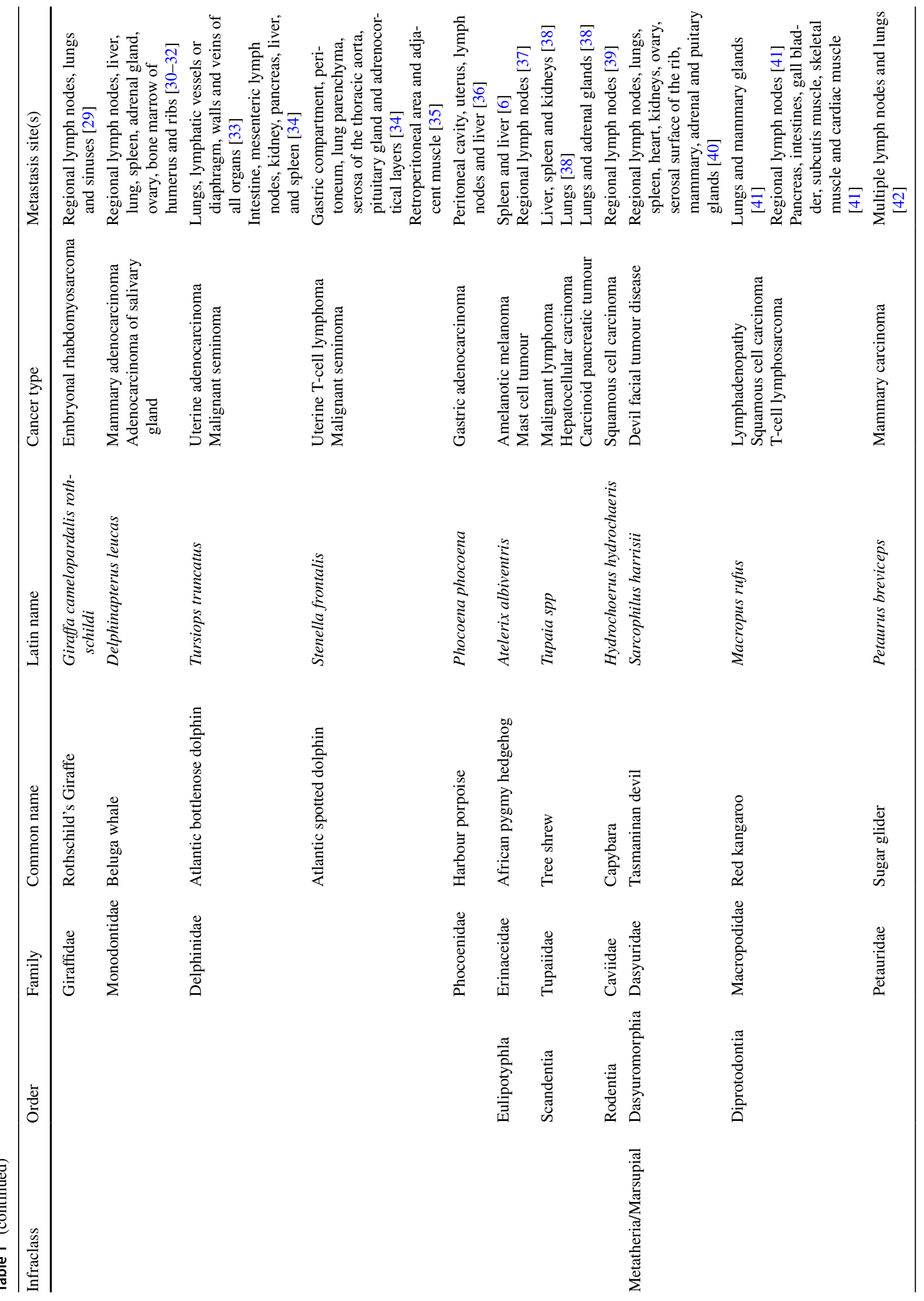


Kaposi's sarcoma, respectively. All of these cancers are known to metastasize resulting in poor prognosis for the patient. Otarine herpesvirus- 1 infection is a known cause of highly metastatic carcinomas of urogenital origin in free-living Californian sea lions (Zalophus californianus, as well as exposure to chemical and plastic waste contaminants in the water) [61]. In a study of Californian sea lions at a marine mammal rehabilitation centre (1979-1994), $76 / 370(21 \%)$ of the animals had gross lesions on postmortem examination, with $66 / 76$ (18\%) having widely metastatic carcinoma (subsequently determined to be of genital origin) [18]. Masses were found in the lungs and liver in $62 \%$ and $56 \%$ of the cases, respectively [19]. Ovine pulmonary carcinoma (OPC, also known as sheep pulmonary adenomatosis or jaagsiekte) is a retrovirus-induced bronchioloalveolar carcinoma [62] with morphological similarities to human bronchioloalveolar carcinoma. Metastases histologically resembling the primary tumor are found in bronchial or mediastinal lymph nodes in up to $10 \%$ of OPC cases, with metastases to other organs including the skeletal muscle, kidneys and lung occurring in $10-50 \%$ of cases, depending on the geographic location of the animals (reviewed in [63]). A recent case study reported progression of canine papillomavirus-associated cutaneous pigmented plaques to metastatic squamous cell carcinoma in two dogs [64].

Reports of spontaneous metastatic tumours in amphibians are uncommon with the majority of incidences being case studies of single animals [48]. However, an exception is the northern leopard frog (Rana pipiens), which is susceptible to Lucké tumour herpesvirus (LTHV)-induced renal adenocarcinoma $[65,66]$. This tumour has the unique property of a metastatic phenotype that is regulated by the internal body temperature of the host. Whilst temperature exerts little effect on growth of the primary tumor, it profoundly affects the process of metastasis, with widespread metastatic colonies (lungs, liver, coelom, ovaries, pancreas, bladder, and other sites) being found in tumour-bearing frogs kept at $28{ }^{\circ} \mathrm{C}$ for 50 days, while those kept at $7{ }^{\circ} \mathrm{C}$ for 98 days or more have either no metastatic lesions or only an occasional small metastatic nodule [67]. Studies of this temperaturedependency metastatic phenotype have revealed that these tumors show increased motility and release of a metalloprotease (which degrades basement membrane collagen) at elevated temperatures [68].

Patterns in disease aetiology observed in marine species may contribute as an environmental biomarker as well as developing an understanding of carcinogen-induced metastasis. Chemical and plastic waste contaminants, such as polycyclic aromatic hydrocarbons (PAHs), polychlorinated biphenyls (PCBs) and organochlorines, are known human carcinogens. Their increasing presence in the oceans (due to human pollution) has been implicated in the development 


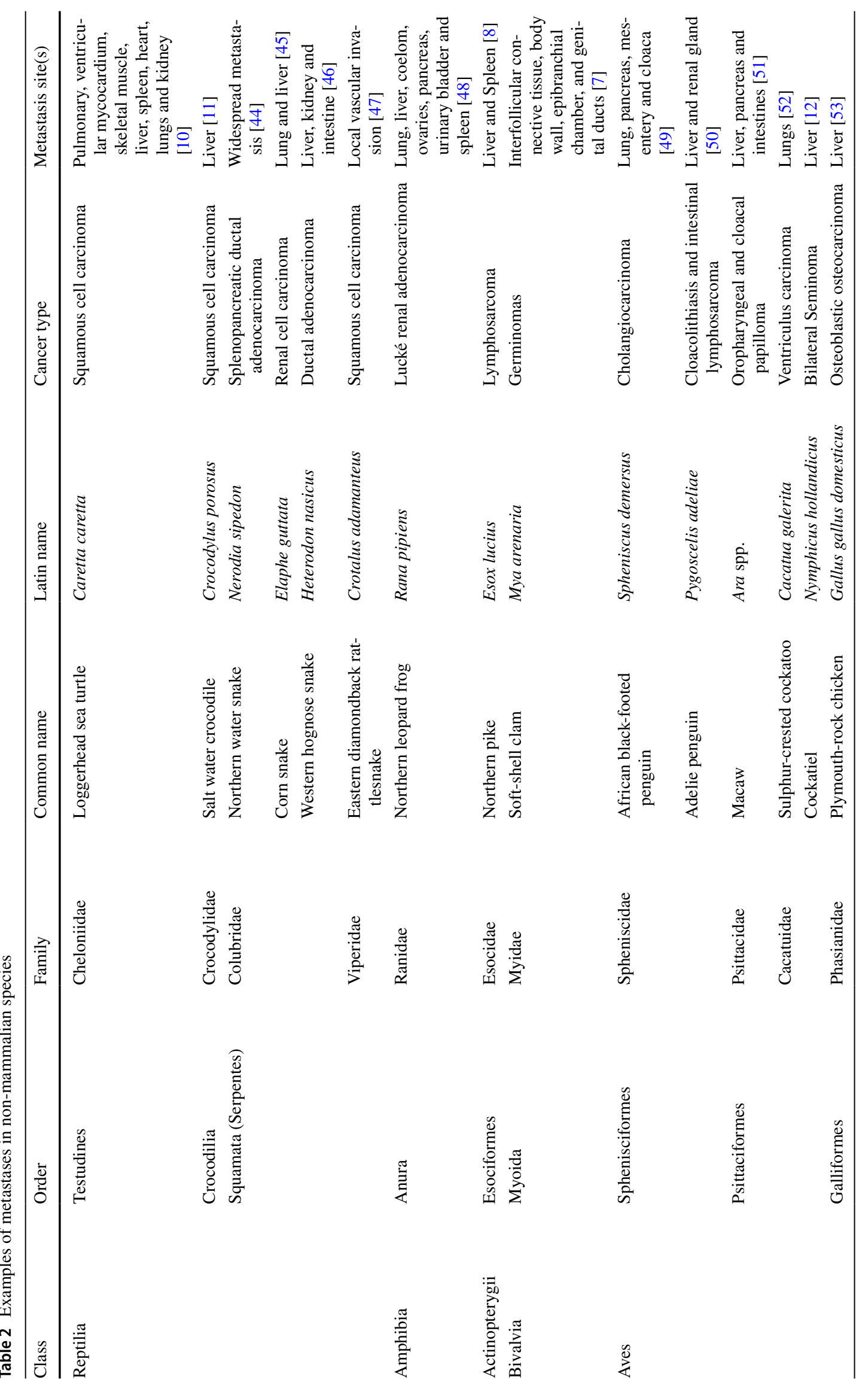


of urogenital carcinomas in Californian sea lions. The blubber of sea lions with genital carcinoma have $85 \%$ higher levels of PCBs than naïve controls [69]. Californian sea lions exhibit a high prevalence of metastatic carcinoma of urogenital origin (UGC) with $26 \%$ of adult sea lion postmortems performed at The Marine Mammal Center in California (during 1998-2012) being affected [61]. Metastasis can occur both locally (abdominal and pelvic lymph nodes, kidney and urinary bladder) and to more distant sites (liver, lungs and spleen) [70].

The role of the immune system in cancer (from tumour initiation to metastatic progression) and how tumour cells avoid elimination by the immune attack is an area of current research [71], and whilst some cancers in animals have no direct human correlates per se, they can provide critical insights into tumour cell evasion of the immune system resulting in metastasis. For example, the clonally transmissible tumours that develop in and around the mouth, head and neck of Tasmanian devils (Sarcophilus harrisii, 'devil facial tumour disease', DFTD) are highly aggressive and frequently metastatic (59/91 cases), primarily spreading to regional lymph nodes and lungs [40]. One reason for the high fatality rate of this cancer is that Tasmanian devils have low genetic diversity (due to a prehistoric bottleneck and persecution from European settlers) and as such have a lack of diversity in most immunological genes, with all populations sharing similar MHC genes, so there is no immune response against the tumour cells [72]. Similar to DTFD, canine transmissible venereal sarcoma (CTVS) is a clonal cell allograft with highly metastatic potential. However, unlike the low diversity of MHC I in the Tasmanian devils, CTVS cells show downregulation of MHC I and a complete absence of MHC II, thus evading host immune recognition, permitting successful transmission and progression [73]. CTVS also causes severe damage to monocyte-derived dendritic cells, which has been proposed as another of its mechanisms for evading host immunity [74].

\section{Histopathological similarities}

A lack of specific tools to appropriately utilise samples from spontaneous metastasis incidences outside of laboratorycontrolled populations may be considered a limitation in investigating alternative models, however there are many successful reports of the diagnostic use of immunohistochemistry for biomarkers that are clinically relevant in the human setting [3]. For example, a cutaneous T cell lymphoma in an antelope (Addax nasomaculatus) with metastatic spread to multiple lymph nodes [24], an intestinal lymphosarcoma in an African black-footed penguin (Spheniscus demersus) with metastatic spread to the liver and kidneys [50], and a uterine T-cell lymphoma in an Atlantic bottle-nosed dolphin (Tursiops truncates) with metastatic spread to the lung, pituitary gland and peritoneum [35], all showed strong immunohistochemical staining for CD3 but not CD79a, confirming the lymphocytes to be of $\mathrm{T}$ cell origin (CD3 and CD79a are used as immunohistochemical markers of $\mathrm{T}$ and B-cell leukaemias/lymphomas in humans, respectively). In another case report, a cutaneous squamous cell carcinoma in a capybara (Hydrochoerus hydrochaeris) with regional lymph node metastases showed positive immunohistochemical staining for cytokeratin AE1/AE3, confirming the cell origin as being epithelial [39]. In addition, a pulmonary adenocarcinoma in a llama (Lama glama) with liver and bone metastases showed positive immunohistochemical staining for pan-cytokeratin, cytokeratin 7 , and cytokeratin 5/6 antibodies and negative staining for vimentin and cytokeratins $8 / 18$ and 20 antibodies, consistent with bronchioloalveolar carcinoma in humans [28].

In humans, metastatic ovarian cancer usually presents with widespread intra-abdominal metastasis remaining confined to the peritoneal cavity, however in cases of aggressive disease there can be lung, liver or central nervous system (CNS) metastases during disease progression. In an Eurasian brown bear (Ursus arctos arctos) with ovarian cancer, metastases were observed in the regional lymph nodes and brain, with immunohistochemistry showing strong positivity for cytokeratin AE1/AE3 [21], an antigen which is expressed by more than $90 \%$ of human ovarian carcinomas [75]. In a recent case report of a giant panda (Ailuropoda melanoleuca) with ovarian cancer, histopathological studies revealed multiple lesions in the lungs, kidneys, perianal tissue and spleen at necropsy, that stained positive by immunohistochemistry for B7-H4, CA125, and HE4, as well as the presence of significantly high serum levels of the tumour antigen AFP [23]. In humans, the combination of HE4 and CA125 expression is currently used in the clinic for accurate diagnosis of malignant ovarian tumours [76], and AFP is used in the clinic as a tumour marker.

Metastatic cutaneous melanoma in humans typically spreads to the lymph nodes, lungs, liver, bone and brain, and immunohistochemical markers commonly used for diagnosis include S-100, HMB-45, MART-1/Melan-A, tyrosinase, and MITF [77]. A case report of a lesser Madagascar hedgehog tenrec (Echinops telfairi) with amelanotic melanoma (presenting as a cutaneous mass on the ear), found extensive metastatic lesions in the spleen and liver, which were strongly HMB- 45 positive and weakly S-100 positive by immunohistochemistry [6]. Another study of amelanotic melanomas in dogs showed strong immunohistochemical staining using rabbit anti-S100 in 26/31 of samples [78]. An uveal melanoma in a dog and its metastasis to the prostate, were also reported to show immunohistochemical positivity for Melan-A [79].

In humans, breast cancer typically spreads to the lymph nodes, bones, liver, lungs and brain. In wild animals there 
have been case reports of mammary adenocarcinomas in a lioness (Panthera leo) with spread to only regional lymph nodes [41] and a camel, llama and Beluga whale with widespread metastases [26, 30]. Interestingly, sections of the adenocarcinoma from the Beluga whale showed strong reactivity with a rabbit anti-human oestrogen receptor antibody [30]. Canine mammary tumour is the most common cancer among female dogs and often becomes fatal due to the development of distant metastases [80]. Metastasis to the regional lymph node is an early step in metastasis and is usually followed by the development of distant metastases, mainly in the lung, ultimately leading to the death of the dog [81, 82].

In dogs with osteosarcomas, $>95 \%$ present with pulmonary micrometastases [83], and in humans, metastatic osteosarcoma typically spreads to the lungs. There has also been a case report of a polar bear (Ursus maritimus) with osteosarcoma that was found to have multiple confluent metastases in all lobes of both lungs [20]. However, osteosarcoma can also spread to other organs such as the bone and brain, and although rare, there are case reports of osteosarcoma patients with liver metastases, as well as a report of an osteoblastic osteosarcoma in a free-range chicken (Gallus gallus domesticus) metastasizing to the liver [53].

The clinical course of tonsillar squamous cell carcinoma (SCC) in humans is aggressive with frequent recurrence and early dissemination (60-80\% of patients have cervical lymph node metastasis at initial diagnosis [84]). SCC of tonsils in dogs are locally invasive and metastasize quite early to regional lymph nodes, with one study reporting $77 \%$ of their necropsy cases showing metastasis to regional lymph nodes or beyond [85]. Similarly, SCC of the tonsil in cats also tends to metastasize early to the regional lymph nodes [86].

Wilms' tumour (nephroblastoma) typically occurs in children and often metastasizes, with those in stage IV (10\% of cases, defined by the presence of hematogenous metastases to the lung, liver, bone, or brain) having a poor prognosis. Metastatic dissemination to distant sites has been reported in animals with nephroblastomas, including a Japanese eel (Anguilla japonica) [87] and a recent a case study of a miniature pinscher dog [88]. Interestingly, the histological appearance of metastatic lesions can be different from that of the primary tumour and in the case of the eel with nephroblastoma where hepatic metastases were found, the metastases differed markedly in histological type from the main primary tumour [87].

ERMS is the most common soft tissue sarcoma occurring in children. Desmin/myogenin/Myo-D1 immunohistochemical positivity is often used to confirm the diagnosis and treatment usually involves surgical excision and adjuvant chemo- or radiation therapy, however survival of patients rapidly decreases with development of metastasis [54]. Correspondingly, there is a necropsy report of an adolescent domestic canine with an invasive neoplasm in the cranial cavity and hepatic metastases, for which a diagnosis of ERMS was confirmed using immunohistochemical analysis for desmin and myogenin [89]. Similarly there is a case report of a young dog with eyelid enlargement (lachrymal gland protrusion) and multiple masses throughout the body, for which a diagnosis of ERMS was confirmed with immunohistochemical positivity of the tumour cells for desmin, myogenin and Myo-D1 [90].

In humans, renal cell carcinoma (RCC) has a great propensity for metastasis with $30 \%$ of patients already showing metastasis at the time of diagnosis, and metastatic RCC is a highly fatal disease [91]. Ninety percent of canine renal epithelial tumours are classified as malignant and metastases are detected in 50-60\% of the cases [92]. In dogs, the most likely metastases sites are lungs, regional lymph node and liver, but occasionally also the brain and skin [92, 93], which is similar to that seen in humans [94]. Interestingly, metastases occur much more frequently in dogs than is reported in cattle with renal cell tumours [93, 95].

\section{Genetic similarities}

Spontaneous tumours in non-laboratory animals are relevant models for human cancer primarily because both the animal population and the tumours themselves are genetically heterogeneous. As with metastatic breast cancer in humans, reduction and aberrant expression of BRCA1 in canine mammary tumours has been found to be significantly associated with malignant characteristics [96]. Similarly, altered derlin-1 and stanniocalcin-1 expression levels are associated with the metastasis of human breast cancer cells and metastisizing canine mammary adenocarcinomas [97]. Microarray analysis of 27 canine mammary carcinomas found 1,011 significantly differentially expressed genes between metastatic and non-metastatic carcinomas, and 265 of these genes were related to human breast cancer genes [98]. In addition, comparison with the van't Veer 70 gene prognostic signature, which reliably identifies human breast cancers with metastatic potential, also found a significant overlap [99]. The claudins are tight junction proteins involved in cell adhesion and polarity, and studies have found reduced expression of claudins in human breast cancers [100], canine mammary carcinomas [101], and feline mammary cancers [102], is associated with a pre-invasion and metastasis phenotype. The human epidermal growth factor receptor 2 (HER2) is overexpressed in around $20-30 \%$ of breast cancers, and is associated with a more aggressive disease and increased mortality. Expression of the feline orthologue of the HER2 gene, $f$-HER2 (whose kinase domain is $92 \%$ similar to the HER2 kinase domain), has been found to be increased in feline mammary carcinoma (FMC) cell lines and tissue samples, and the anti-human HER2 antibody strongly 
stained 13/36 (36\%) FMC archival tissues samples (FMC is a highly aggressive, mainly hormone receptor-negative cancer, that been proposed as a model for poor prognosis triple negative breast cancer in humans) [103].

In human osteosarcoma, p53 has been shown to be an effective prognostic marker and upregulated p53 is associated with a shorter survival time [104], and this has also been associated with poor prognosis in canine osteosarcoma [105]. In addition to overall prognosis, genes such as the proto-oncogenic receptor $c$-Met, have been implicated in the development of metastasis in humans osteosarcoma [106], and in canine osteosarcoma, $c$-Met has been implicated in lymphatic spread [107]. The membrane cytoskeleton linking molecule, ezrin, has been associated with a shorted survival time (due to pulmonary metastasis) in both humans and dogs with osteosarcoma [108, 109].

Gastrointestinal stromal tumours (GISTs) are an aggressive cancer type that occurs in both humans and dogs [110], and have a poor prognosis due to the tumour commonly spreading to the liver and peritoneal cavity. In both species, the GISTs arise due to oncogenic mutations in the KIT tyrosine kinase, which also drives canine cutaneous mast cell tumours [111]. There are also case reports of a mast cell tumour in a llama, which exhibited positive membrane KIT expression [112], and a captive opossum (Didelphis virginiana), in which $c$-KIT positive cancerous cells were found to have spread to distant sites, including the liver, skin, kidney, pancreas and spleen [43].

Although there are conflicting reports of the presence of $B R A F, N R A S$ and $c-K I T$ mutations in canine mucosal melanomas, possibly reflecting the complexity and heterogeneity of cancer seen in humans, a strong parallel between human and canine mucosal melanoma is frequent in activation of the RAS/MAPK and/or PI3K/AKT/mTOR signalling pathways $[57,113]$ with synergistic targeted inhibition of MEK and dual PI3K/mTOR inhibiting tumour growth of a canine melanoma cell line in nu/nu athymic mice [114]. Recently, microarray expression profiling found upregulated expression of 8 miRNAs that could discriminate between metastasizing and non-metastasizing uveal melanomas in dogs, and 3 of these were found to be implicated as potential "metastasis activators" in human cutaneous melanoma [115].

\section{Therapeutic similarities}

Immunotherapeutic targeting of immune checkpoint molecules (such as PD-1, PD-L1 and CTLA-4) have been widely used for some human cancers in the last 7 years, particularly melanoma, with Ipilimumab (CTLA-4 monoclonal antibody) treatment improving overall survival in patients with previously treated metastatic melanoma [116]. The expression of CTLA-4 and PD-1 has been observed on lymphocytes of dogs with mastocytoma, melanoma, and renal cell carcinoma, and studies using a human monoclonal antibody against PD-L1 has confirmed expression of PD-L1 on a number of canine tumour biopsies [117]. More recently, a cancer research report (2018) by the Flatcoated Retriever Society, which thanked the $>500$ owners "who have kindly offered precious information for the good of the breed when grieving the loss of their beloved pet", found that all their cases of histiocytic sarcomas (28 in total) showed expression of PD-L1. A pilot clinical trial to assess the clinical efficacy of a canine chimeric monoclonal antibody targeting PD-L1 in canine oral malignant melanoma or undifferentiated sarcoma showed a reduced tumour burden in some dogs, with the survival of dogs with metastatic oral malignant melanoma being prolonged in the antibody treatment group $(n=4)$ compared to an historical control group $(n=15)$ treated by standard therapies [118].

In humans, imatinib has been demonstrated to be highly effective in delaying progression and prolonging life in patients with metastatic GIST [119]. In a case report of a mixed-breed dog with GIST, five months after surgical resection of the tumour the recurrence of GIST with multiple disseminated abdominal lesions was detected, however after 2 months of treatment with imatinib mesylate, the dog achieved complete remission [120]. Tyrosine kinase inhibition by imatinib mesylate has also been demonstrated to have clinical activity on mast cell tumours in dogs [121].

Spontaneous feline oral squamous cell carcinoma (FOSCC) and head and neck squamous cell carcinoma (HNSCC) in humans share molecular markers (EGFR, VEGF, and p53), tumour biology, treatment and prognostic similarities [122, 123], with both showing comparable rates of development of metastasis (15-20\%) [124]. A multimodal treatment approach is commonly used in both cats and humans with FOSCC/HNSCC, including surgery, radiation therapy and chemotherapy. Chemotherapeutic drugs routinely used in HNSCC include cisplatin and piroxicam, and novel therapeutic agents such as cetuximab, gefitinib and masitinib have also been investigated in cats [123].

\section{Therapeutic implications}

Anti-metastatic therapeutics are a high-potential category of drugs but require complex development, which has been deprioritised by the pharmaceutical industry due to latestage failures in clinical development, despite extensive evidence in preclinical models [125]. The current framework for cancer therapeutics is unfavourable towards antimetastatic agents with a focus on clinical outcomes such as tumour shrinkage, rather than inhibition of metastasis. However, the implementation of comparative oncology strategies has already facilitated some progression in clinical metastasis. 
Combination therapy remains the basis for clinical management of many types of cancers, as the use of multiple treatments may be more effective in targeting the heterogeneity within the tumour population and avoid the development of resistance. To this end, the use of a procaspase-activating compound 1 (PAC-1) in combination with doxorubicin was evaluated in 10 companion canines with metastatic osteosarcoma or lymphoma, and found to be efficacious in 50\% (3/6) of osteosarcoma patients and $100 \%$ (4/4) of lymphoma patients [126]. Since this study, a Phase I clinical trial was launched in 2017 for PAC-1 in combination with temozolomide in patients with high grade glioma after progression following standard first line therapy (ClinicalTrials.gov Identifier: NCT03332355; study due for completion June 2019).

In both humans and dogs, treatment for osteosarcoma involves surgery to remove primary tumours and on occasion distant metastasis, combined with neoadjuvant and/ or adjuvant chemotherapy $[127,128]$. The similarities in disease and progression between humans and dogs, alongside utilising the compressed life-span of the companion canines, offers an opportunity to quickly identify anti-metastatic therapeutics in veterinary trials that can be used to inform new treatment options for human patients. There are several examples of where this opportunity has been harnessed. Promising results from a randomized study [129] using the immunomodulator mifamurtide (LiposomalMuramyl TriPeptide-PhosphatidylEthanolamine: L-MTP$\mathrm{PE})$ on dogs with spontaneous osteosarcoma, in addition to subsequent studies, prompted clinical studies with this drug in humans [130]. A Phase II trial using L-MTP-PE in patients with osteosarcoma and synchronous or metachronous lung metastases concluded that there was evidence for a biological effect of L-MTP-PE on osteosarcoma lung metastases [131]. Another example is with the use of HER2 immunotherapy. A phase I dose escalation clinical trial in dogs with osteosarcoma found that ADXS31-164 (Listeria expressing a chimeric human HER2/neu fusion protein) administered in the setting of minimal residual disease could induce HER2/neu-specific immunity and may reduce the incidence of metastatic disease and prolong overall survival [132]. Following from this success, Advaxis recently licensed (at the end of 2018) ADXS-HER2 for evaluation (clinical trials) in the treatment of osteosarcoma in human patients. Excitingly, to addresses the current limitations in the drug discovery and development process for anti-metastatic therapeutics, Vuja De Sciences and Ethos Veterinary Health announced (at the end of 2018) they would be collaborating to empower metastasis-focused drug development, starting with osteosarcoma.

\section{Conclusion}

The use of non-laboratory bred animals ('metastasis in the wild'), may present its challenges but offers a more clinically-relevant model than the traditional laboratory mouse and provides a unique opportunity for clinical and experimental research that would benefit both humans and animals. Spontaneous tumours in non-laboratory animals represent relevant models for human cancer and metastasis for many reasons. A key importance is that similar to the human population, non-laboratory animals are a genetically heterogeneous population, as are the cancers and metastases they develop. In addition, they are typically larger in size and have a longer life-span than laboratory mice, and are affected by the same environmental stimuli (pollutants, infections) and disease states (diabetes, obesity, stress) that face humans. Furthermore, recent advancements in immunotherapy make the immune system a very contemporary topic in targeting metastasis, but the complexity of the human immune system can be difficult to mimic in a laboratory setting. Often kept in a controlled environment, laboratory animals exhibit differences in pathogen and microbial exposure which will elicit different immune responses, not necessarily representative of a human cancer patient. Moreover, in human-derived experimental metastasis models, immunedeficient murine hosts are required to avoid rejection of the cancer cells, further removing the set-up from relevance to the clinical setting.

In non-domestic animals, there exists the opportunity to observe the course of metastatic development and progression in the absence of therapeutic intervention (rarely achievable in human studies), to allow research into the fundamental biology driving these processes. In domestic animals, particularly companion animals, there is generally a strong emotional attachment to the animal, which translates to a high level of compliance for drug trials and attending follow up appointments, thus affording the opportunity to test new therapeutic regimes (again, rarely achievable in human studies). Thus with the number of surplus tissues, compliance to necropsy, cross-species immunoreactivity, comparable histopathological analysis and diagnosis, in addition to the option of treated or non-treated individuals, veterinary-seen animals are an economical, under-used resource in metastasis research. Each patient, whether human or animal, holds an exclusive ability to individually contribute to experimental and clinical metastasis research, and initiatives to integrate human and veterinary oncology research programs (such as the National Cancer Institute's Center for Cancer Research (CCR) "Comparative Oncology Program") will further contribute to expanding our understanding of metastasis and the development of therapeutic opportunities. 
OpenAccess This article is distributed under the terms of the Creative Commons Attribution 4.0 International License (http://creativeco mmons.org/licenses/by/4.0/), which permits unrestricted use, distribution, and reproduction in any medium, provided you give appropriate credit to the original author(s) and the source, provide a link to the Creative Commons license, and indicate if changes were made.

\section{References}

1. Gardner D (1996) Spontaneous squamous cell carcinomas of the oral region in domestic animals: a review and consideration of their relevance to human research. Oral Dis 2(2):148-154. https ://doi.org/10.1111/J.1601-0825.1996.Tb00216.X

2. Mak IW, Evaniew N, Ghert AM (2014) Lost in translation: animal models and clinical trials in cancer treatment. Am J Transl Res 6(2):114. https://doi.org/10.2147/Dddt.S49584

3. Vail DM, Macewen EG (2000) Spontaneously occurring tumors of companion animals as models for human cancer. Cancer Invest 18(8):781-792. https://doi.org/10.3109/07357900009012210

4. Owen LN, WH Organization (1980) Tnm classification of tumours in domestic animal. https://www.Who.Int/

5. Newman S, Smith S (2006) Marine mammal neoplasia: a review. Vet Pathol 43(6):865-880. https://doi.org/10.1354/Vp.43-6-865

6. Harrison TM et al (2010) Treatment of an amelanotic melanoma using radiation therapy in a lesser madagascar hedgehog tenrec (Echinops telfairi). J Zoo Wildl Med 41(1):152-157. https://doi. org/10.1638/2008-0215.1

7. Carballal MJ et al (2015) Neoplastic diseases of marine bivalves. J Invertebr Pathol 131:83-106. https://doi.org/10.1016/J. Jip.2015.06.004

8. Schlumberger HG, Lucké B (1948) Tumors of fishes, amphibians, and reptiles. Cancer Res 8(12):657-753

9. Sykes Iv JM, Trupkiewicz JG (2006) Reptile neoplasia at the philadelphia zoological garden, 1901-2002. J Zoo Wildl Med 37(1):11-19. https://doi.org/10.1638/04-112.1

10. Oros J et al (2004) Metastatic squamous cell carcinoma in two loggerhead sea turtles caretta caretta. Dis Aquat Org 58(23):245-250. https://doi.org/10.3354/Dao058245

11. Hill A, Dennis M, Pyne AM (2016) Squamous cell carcinoma with hepatic metastasis in a saltwater crocodile (Crocodylus porosus). Aust Vet J 94(3):83-86. https://doi.org/10.1111/ Avj.12404

12. Saied A et al (2011) Bilateral seminoma with hepatic metastasis in a cockatiel (Nymphicus hollandicus). J Avian Med Surg 25(2):126-131. https://doi.org/10.1647/2010-012.1

13. Rothschild BM, Witzke BJ, Hershkovitz AI (1999) Metastatic cancer in the jurassic. Lancet 354(9176):398. https://doi. org/10.1016/S0140-6736(99)01019-3

14. Firdous A et al (2013) Mammary adenocarcinoma in lioness. https://doi.org/10.13005/Bbra/1155

15. Nakagaki KY et al (2015) Transitional cell carcinoma of urinary bladder with metastasis in lumbar vertebrae and spinal cord compression in an ocelot (Leopardus pardalis). Pesquisa Veterinária Brasileira 35(1):75-79. https://doi.org/10.1590/S0100-736x2 015000100015

16. Goodnight AL et al (2013) Squamous cell carcinoma of the anal sac in a spotted hyena (Crocuta crocuta). J Zoo Wildl Med 44(4):1068-1074. https://doi.org/10.1638/2012-0153r1.1

17. Carpenter JW et al (1980) Metastatic, papillary cystadenocarcinoma of the mammary gland in a black-footed ferret. J Wildl Dis 16(4):587-592. https://doi.org/10.7589/0090-3558-16.4.587

18. Lipscomb T et al (2000) Common metastatic carcinoma of California sea lions (Zalophus californianus): evidence of genital origin and association with novel gammaherpesvirus. Vet Pathol 37(6):609-617. https://doi.org/10.1354/Vp.37-6-609

19. Gulland F et al (1996) Metastatic carcinoma of probable transitional cell origin in 66 free-living California sea lions (Zalophus californianus) 1979 to 1994. J Wildl Dis 32(2):250-258. https:// doi.org/10.7589/0090-3558-32.2.250

20. Ponomar'kov V, Khutorianskiǔ A (1995) A case of osteosarcoma in a white polar bear. Arkhiv Patologii 57(5):81-83

21. Rossi G et al (2016) Metastasizing ovarian carcinoma in an Eurasian brown bear (Ursus arctos arctos): a case report. Slov Vet Res 53(2):99-106

22. Vashist VS, Rattan SK, And BB, Gupta (2013) Papillary cystadenocarcinoma of the mammary gland with metastases to the gastrointestinal tract in a Himalayan brown bear (Ursus arctos). J Zoo Wildl Med 44(2):453-456. https://doi.org/10.1638/20110093r1.1

23. Gao Q et al (2018) A case of giant panda ovarian cancer diagnosis and histopathology. BMC Vet Res 14(1):311. https://doi. org/10.1186/S12917-018-1630-X

24. Gyimesi ZS et al (2017) Cutaneous T-cell lymphoma with lymph node metastasis in an adult addax (Addax nasomaculatus). J Zoo Wildl Med 48(3):933-936. https://doi.org/10.1638/2016-0285.1

25. Mollat WH, Gailbreath KL, And GM, Orbell (2009) Metastatic malignant melanoma in an alpaca (Vicugna pacos). J Vet Diagn Investig 21(1):141-144. https://doi.org/10.1177/1040638709 02100124

26. Gall DA et al (2006) Imaging diagnosis - pulmonary metastases in new world camelids. Vet Radiol Ultrasound 47(6):571-573. https://doi.org/10.1111/J.1740-8261.2006.00187.X

27. Klopfleisch R, Van Der Grinten E, Gruber AD (2009) Metastatic uterine adenocarcinoma and hepatic lipomatosis in a llama (Lama glama). J Vet Diagn Investig 21(2):280-282. https://doi. org/10.1177/104063870902100222

28. Ramos-Vara JA, And MA, Miller (2002) Metastatic pulmonary adenocarcinoma in a llama (Lama glama). J Vet Diagn Investig 14(4):328-331. https://doi.org/10.1177/104063870201400410

29. Woc-Colburn M et al (2010) Embryonal rhabdomyosarcoma in a Rothschild's giraffe (Giraffa camelopardalis rothschildi). J Zoo Wildl Med 41(4):717-720. https://doi.org/10.1638/2009-0195.1

30. Mikaelian I et al (1999) Metastatic mammary adenocarcinomas in two beluga whales (Delphinapterus leucas) from the $\mathrm{St}$ Lawrence Estuary, Canada. Br Med J. https://doi.org/10.1136/ Vr.145.25.738

31. Girard C et al. (1991) Adenocarcinoma of the salivary gland in a beluga whale (Delphinapterus leucas). J Vet Diagn Investig 3(3):264-265. https://doi.org/10.1177/104063879100300317

32. Martineau D (2002) Cancer in wildlife, a case study: beluga from the St. Lawrence Estuary, Quebec, Canada. Environ Health Perspect 110(3):285. https://doi.org/10.1289/Ehp.02110 285

33. Sánchez J et al (2002) Uterine adenocarcinoma with generalised metastasis in a bottlenose dolphin Tursiops Truncatus from Northern Patagonia, Argentina. Dis Aquat Org 48(2):155-159. https://doi.org/10.3354/Dao048155

34. Estep J et al (2005) Malignant seminoma with metastasis, sertoli cell tumor, and pheochromocytoma in a spotted dolphin (Stenella frontalis) and malignant seminoma with metastasis in a bottlenose dolphin (Tursiops truncatus). Vet Pathol 42(3):357-359. https://doi.org/10.1354/Vp.42-3-357

35. Díaz-Delgado J et al (2015) Primary uterine T-cell lymphoma with metastasis in an atlantic spotted dolphin (Stenella frontalis), Canary Islands, Spain. J Wildl Dis 51(2):538-541. https://doi. org/10.7589/2014-08-199

36. Breuer E, Krebs B, Hofmeister AR (1989) Metastasizing adenocarcinoma of the stomach in a harbor porpoise, 
Phocoena-Phocoena. Dis Aquat Org 7(3):159-163. https://doi. org/10.3354/Dao007159

37. Raymond JT, White MR, And EB, Janovitz (1997) Malignant mast cell tumor in an African hedgehog (Atelerix albiventris). J Wildl Dis 33(1):140-142. https://doi. org/10.7589/0090-3558-33.1.140

38. Darai G, Al Et (1982) Spontaneous malignomas in Tupaia (Tree shrew). Am J Primatol 2(2):177-189. https://doi.org/10.1002/ Ajp. 1350020206

39. Hamano $\mathrm{T}$ et al (2014) Squamous cell carcinoma in a capybara (Hydrochoerus hydrochaeris). J Vet Med Sci 76(9):1301-1304. https://doi.org/10.1292/Jvms.13-0395

40. Loh R et al (2006) The pathology of devil facial tumor disease (Dftd) in tasmanian devils (Sarcophilus harrisii). Vet Pathol 43(6):890-895. https://doi.org/10.1354/Vp.43-6-890

41. Suedmeyer WK, Johnson G (2007) Survey of neoplasia in red kangaroos (Macropus rufus), 1992-2002, in a zoological collection. J Zoo Wildl Med 38:231-239. https://doi.org/10.1638/10427260(2007)038\%5B0231:Sonirk\%5D2.0.Co;2

42. Churgin SM, Al Et (2015) Metastatic mammary adenocarcinoma in a sugar glider (Petaurus breviceps). J Exot Pet Med 24(4):441445. https://doi.org/10.1053/J.Jepm.2015.08.011

43. Pope JP, Donnell RL (2017) Spontaneous neoplasms in captive virginia opossums (Didelphis virginiana): a retrospective case series (1989-2014) and review of the literature. J Vet Diagn Investig 29(3):331-337. https://doi.org/10.1177/1040638717 704017

44. Matthews ME, Al Et (2014) Splenopancreatic ductal adenocarcinoma with multiorgan metastasis in a northern water snake (Nerodia sipedon). J Zoo Wildl Med 45(2):437-440. https://doi. org/10.1638/2013-0199r.1

45. Barten SL et al (1994) Renal cell carcinoma with metastases in a corn snake (Elaphe guttata). J Zoo Wildl Med 25:123-127. https ://doi.org/10.1177/1040638716661380

46. Stern W, Velguth AKE, And J, D'agostino (2010) Metastatic ductal adenocarcinoma in a western hognose snake (Heterodon nasicus). J Zoo Wildl Med 41(2):320-324. https://doi. org/10.1638/2008-0207r1.1

47. Anderson ET (2010) Et Al., Squamous cell carcinoma with vascular invasion in a diamondback rattlesnake (Crotalus adamanteus). J Zoo Wildl Med 41(4):745-748. https://doi. org/10.1638/2010-0096.1

48. Anver MR (1989) Metastases in amphibians, in comparative aspects of tumor development. Springer, New York, 55-57

49. Renner MS, Zaias J, Bossart GD (2001) Cholangiocarcinoma with metastasis in a captive adelie penguin (Pygoscelis adeliae). J Zoo Wildl Med 32(3):384-386. https://doi.org/10.1638/10427260(2001)032\%5B0384:Cwmiac\%5D2.0.Co;2

50. Jones KL et al (2014) Cloacolithiasis and intestinal lymphosarcoma in an African black-footed penguin (Spheniscus demersus). J Zoo Wildl Med 45(2):446-449. https://doi.org/10.1638/20130244r.1

51. Kennedy F et al (1996) Oropharyngeal and cloacal papillomas in two macaws (Ara Spp.) with neoplasia with hepatic metastasis. J Avian Med Surg 10:89-95

52. Campbell TW, Turner O (1999) Carcinoma of the ventriculus with metastasis to the lungs in a sulphur-crested cockatoo ( $\mathrm{CaCa}$ tua galerita). J Avian Med Surg 13:265-268

53. Dittmer K et al (2012) Primary bone tumors in birds: a review and description of two new cases. Avian Dis 56(2):422-426. https://doi.org/10.1637/9854-071911-Case.1

54. Pontes Flávia-Sirotheau-Correa J-I et al (2018) Clinicopathological analysis of head and neck rhabdomyosarcoma: a series of 10 cases and literature review. Med Oral Pathol Oral Cir Bucal 23(2):E188. https://doi.org/10.4317/Medoral.22106
55. Gillem JM, Sullivan L, Sorenmo KU (2018) Diagnosis and multimodal treatment of metastatic maxillofacial juvenile embryonal rhabdomyosarcoma in a young golden retriever. J Am Anim Hosp Assoc 54(5):E545-05. https://doi.org/10.5326/Jaaha-Ms-6662

56. Travis RC, Key TJ (2003) Oestrogen exposure and breast cancer risk. Breast Cancer Res 5(5):239. https://doi.org/10.1186/Bcr62 8

57. Khanna C et al (2006) The dog as a cancer model. Nat Biotechnol 24(9):1065. https://doi.org/10.1038/Nbt0906-1065b

58. Carmichael A (2006) Obesity and prognosis of breast cancer. Obes Rev 7(4):333-340. https://doi.org/10.1111/J.1467789x.2006.00261.X

59. Lim H (2015) Obesity, expression of adipocytokines, and macrophage infiltration in canine mammary tumors. Vet $\mathrm{J}$ 203(3):326-331. https://doi.org/10.1016/J.Tvj1.2015.01.005

60. Arita Y et al (1999) Paradoxical decrease of an adipose-specific protein, adiponectin, in obesity. Biochem Biophys Res Commun 257(1):79-83. https://doi.org/10.1006/Bbrc.1999.0255

61. Browning HM et al (2015) Common cancer in a wild animal: the California sea lion (Zalophus californianus) as an emerging model for carcinogenesis. Phil Trans R Soc B 370(1673):20140228. https://doi.org/10.1098/Rstb.2014.0228

62. Stünzi H, Head K, Nielsen AS (1974) Tumours of the lung. Bull World Health Org 50(1-2):9

63. Demartini JC, Rosadio RH, And MD, Lairmore (1988) The etiology and pathogenesis of ovine pulmonary carcinoma (sheep pulmonary adenomatosis). Vet Microbiol 17(3):219-236. https ://doi.org/10.1016/0378-1135(88)90067-3

64. Luff J et al (2016) Two canine papillomaviruses associated with metastatic squamous cell carcinoma in two related Basenji dogs. Vet Pathol 53(6):1160-1163. https://doi.org/10.1177/03009 85816630795

65. Lucké B (1934) A neoplastic disease of the kidney of the frog, Rana pipiens. Am J Cancer 20(2):352-379. https://doi. org/10.1158/Ajc. 1934.352

66. Lucké B (1934) A neoplastic disease of the kidney of the frog, Rana pipiens: II. On the occurrence of metastasis. Am J Cancer 22(2):326-334. https://doi.org/10.1158/Ajc.1934.326

67. Lucké B, Schlumberger H (1949) Neoplasia in cold-blooded vertebrates. Physiol Rev 29(2):91-126. https://doi.org/10.1152/ Physrev.1949.29.2.91

68. Mckinnell RG, Tarin D (1984) Temperature-dependent metastasis of the lucke renal carcinoma and its significance for studies on mechanisms of metastasis. Cancer Metastasis Rev 3(4):373-386. https://doi.org/10.1007/Bf00051461

69. Ylitalo GM et al (2005) The role of organochlorines in cancer-associated mortality in California sea lions (Zalophus californianus). Mar Pollut Bull 50(1):30-39. https://doi. org/10.1016/J.Marpolbul.2004.08.005

70. Colegrove K, et al(2009) Tumor morphology and immunohistochemical expression of estrogen receptor, progesterone receptor, P53, and Ki67 in urogenital carcinomas of California sea lions (Zalophus californianus). Vet Pathol 46(4):642-655. https://doi.org/10.1354/Vp.08-Vp-0214-C-Fl

71. Gonzalez H, Hagerling C, Werb Z (2018) Roles of the immune system in cancer: from tumor initiation to metastatic progression. Genes Dev 32(19-20):1267-1284. https://doi. org/10.1101/Gad.314617.118

72. Woods GM et al. (2015) Immunology of a transmissible cancer spreading among tasmanian devils. J Immunol 195(1):23-29. https://doi.org/10.4049/Jimmunol.1500131

73. Mcaloose D, Newton AL (2009) Wildlife cancer: a conservation perspective. Nat Rev Cancer 9(7):517. https://doi. org/10.1038/Nrc2665

74. Liu C-C et al (2008) Transient downregulation of monocytederived dendritic-cell differentiation, function, and survival 
during tumoral progression and regression in an in vivo canine model of transmissible venereal tumor. Cancer Immunol Immunother 57(4):479-491. https://doi.org/10.1007/S0026 2-007-0386-0

75. Gitsch $\mathrm{G}$ et al (1992) The differential diagnosis of primary peritoneal papillary tumors. Arch Gynecol Obstetr 251(3):139144. https://doi.org/10.1007/Bf02718376

76. Andersen MR et al (2010) Use of a symptom index, Ca125, and He4 to predict ovarian cancer. Gynecol Oncol 116(3):378-383. https://doi.org/10.1016/J.Ygyno.2009.10.087

77. Ohsie SJ et al (2008) Immunohistochemical characteristics of melanoma. J Cutan Pathol 35(5):433-444. https://doi.org/10. 1111/J.1600-0560.2007.00891.X

78. Sandusky G Jr, Carlton W, Wightman AK (1985) Immunohistochemical staining for S100 Protein in the diagnosis of canine amelanotic melanoma. Vet Pathol 22(6):577-581. https://doi. org/10.1177/030098588502200611

79. Delgado E et al (2016) Late prostatic metastasis of an uveal melanoma in a miniature schnauzer dog. Clin Case Rep 4(7):647-652. https://doi.org/10.1002/Ccr3.536

80. Benjamin S, Lee A, Saunders AW (1999) Classification and behavior of canine mammary epithelial neoplasms based on life-span observations in beagles. Vet Pathol 36(5):423-436. https://doi.org/10.1354/Vp.36-5-423

81. Misdorp W, Hart A (1979) Canine mammary cancer: I. Prognosis. J Small Anim Pract 20(7):385-394. https://doi. org/10.1111/J.1748-5827.1979.Tb06743.X

82. Misdorp W, Hart A (1979) Canine mammary cancer: II. Therapy and causes of death. J Small Anim Pract 20(7):395-404. https://doi.org/10.1111/J.1748-5827.1979.Tb06744.X

83. Biller B et al (2016) Aaha oncology guidelines for dogs and cats. J Am Anim Hosp Assoc 52(4):181-204. https://doi. org/10.5326/Jaaha-Ms-6570

84. Lee SY et al (2011) Expression of matrix metalloproteinases and their inhibitors in squamous cell carcinoma of the tonsil and their clinical significance. Clin Exp Otorhinolaryngol 4(2):88. https://doi.org/10.3342/Ceo.2011.4.2.88

85. Todoroff R, Brodey R (1979) Oral and pharyngeal neoplasia in the dog: a retrospective survey of 361 cases. J Am Vet Med Assoc 175(6):567

86. Carpenter JL, Andrews LK, Holzworth AJ (1987) Tumors and tumor-like lesions. Dis Cat Med Surg 1:506-507. https://doi. org/10.1007/978-3-540-49084-5_6

87. Masahito P, et al. (1992) Nephroblastomas in the Japanese eel, Anguilla japonica Temminck and Schlegel. Cancer Res 52(9):2575-2579

88. Chen B, Li W-T, Wang F-I (2018) A blastema-predominant canine renal nephroblastoma with gingival metastasis: case report and literature review. J Vet Diagn Investig 30(3):430-437. https://doi.org/10.1177/1040638718762560

89. Illanes $\mathrm{O}$ (2002) Juvenile parameningeal rhabdomyosarcoma in a dog causing unilateral denervation atrophy of masticatory muscles. J Comp Pathol 126(4):303-307. https://doi.org/10.1053/ Jcpa.2001.0546

90. Kato Y et al (2012) Orbital embryonal rhabdomyosarcoma with metastasis in a young dog. J Comp Pathol 147(2-3):191-194. https://doi.org/10.1016/J.Jcpa.2011.12.011

91. Choi JB (2011) Changes in clinicopathological characteristics of renal cell carcinoma in the past 25 years: a single-center experience. Korean J Urol 52(2):110-114. https://doi.org/10.4111/ Kju.2011.52.2.110

92. Klein M et al (1988) Canine primary renal neoplasms: a retrospective review of 54 cases. J Am Anim Hosp Assoc 24:443-452
93. Meuten DJ, Meuten TL (2016) Tumors of the urinary system. In: Meuten DJ (ed) Tumors in domestic animals. Wiley, Hoboken, pp 632-688. https://doi.org/10.1002/9781119181200.Ch15

94. Gong J et al (2016) Metastasis in renal cell carcinoma: biology and implications for therapy. Asian J Urol 3(4):286-292. https ://doi.org/10.1016/J.Ajur.2016.08.006

95. Kelley L et al (1996) A retrospective study of multicentric bovine renal cell tumors. Vet Pathol 33(2):133-141. https://doi. org/10.1177/030098589603300202

96. Nieto A et al (2003) BRCA1 expression in canine mammary dysplasias and tumours: relationship with prognostic variables. J Comp Pathol 128(4):260-268. https://doi.org/10.1053/ Jcpa.2002.0631

97. Klopfleisch R, And A, Gruber (2009) Derlin-1 and stanniocalcin-1 are differentially regulated in metastasizing canine mammary adenocarcinomas. J Comp Pathol 141(2-3):113-120. https ://doi.org/10.1016/J.Jcpa.2008.09.010

98. Klopfleisch R et al. (2010) Proteome of metastatic canine mammary carcinomas: similarities to and differences from human breast cancer. J Proteome Res 9(12):6380-6391. https://doi. org/10.1021/Pr100671c

99. Van't Veer LJ et al (2002) Gene expression profiling predicts clinical outcome of breast cancer. Nature 415(6871):530

100. Sauer $T$ et al (2005) Reduced expression of claudin-7 in fine needle aspirates from breast carcinomas correlate with grading and metastatic disease. Cytopathology 16(4):193-198. https:// doi.org/10.1111/J.1365-2303.2005.00257.X

101. Tabaries $S$ et al (2011) Claudin-2 is selectively enriched in and promotes the formation of breast cancer liver metastases through engagement of integrin complexes. Oncogene. 30(11):1318. https ://doi.org/10.1038/Onc.2010.518

102. Flores A et al (2014) Reduced expression of claudin-2 is associated with high histological grade and metastasis of feline mammary carcinomas. J Comp Pathol 150(2-3):169-174. https://doi. org/10.1016/J.Jcpa.2013.09.004

103. De Maria R et al (2005) Spontaneous feline mammary carcinoma is a model of Her2 overexpressing poor prognosis human breast cancer. Cancer Res 65(3):907-912

104. Fu H-L et al (2013) Systematic review of a p53 as a biomarker of survival in patients with osteosarcoma. Tumor Biol 34(6):38173821. https://doi.org/10.1007/S13277-013-0966-X

105. Kirpensteijn J et al (2008) Tp53 gene mutations in canine osteosarcoma. Vet Surg 37(5):454-460. https://doi.org/10.1111/ J.1532-950x.2008.00407.X

106. Birchmeier C et al (2003) Met, metastasis, motility and more. Nat Rev Mol Cell Biol 4(12):915. https://doi.org/10.1038/Nrm1261

107. Fieten H (2009) Expression of hepatocyte growth factor and the proto-oncogenic receptor c-Met in canine osteosarcoma. Vet Pathol 46(5):869-877. https://doi.org/10.1354/ Vp.08-Vp-0155-F-Fl

108. Xu-dong S, et al. (2009) Expression of ezrin correlates with lung metastasis in Chinese patients with osteosarcoma. Clin Investig Med 32(2):180-188. https://doi.org/10.25011/Cim.V32i2.6036

109. Jaroensong $\mathrm{T}$ et al (2012) Effects of transplantation sites on tumour growth, pulmonary metastasis and ezrin expression of canine osteosarcoma cell lines in nude mice. Vet Comp Oncol 10(4):274-282. https://doi.org/10.1111/J.1476-5829.2011.00294 .X

110. Frost D, Lasota J, Miettinen AM (2003) Gastrointestinal stromal tumors and leiomyomas in the dog: a histopathologic, immunohistochemical, and molecular genetic study of 50 cases. Vet Pathol 40(1):42-54. https://doi.org/10.1354/Vp.40-1-42

111. Gregory-Bryson E et al (2010) Canine and human gastrointestinal stromal tumors display similar mutations in c-KIT exon 11. BMC Cancer. 10(1):559. https://doi.org/10.1186/1471-2407-10-559 
112. Lin T-Y et al (2010) Mast cell tumors in a llama (Lama glama). $\mathrm{J}$ Vet Diagn Investig 22(5):808-811. https://doi.org/10.1177/10406 3871002200531

113. Hernandez B et al (2018) Naturally occurring canine melanoma as a predictive comparative oncology model for human mucosal and other triple wild-type melanomas. Int J Mol Sci 19(2):394. https://doi.org/10.3390/Ijms19020394

114. Wei BR et al (2016) Synergistic targeted inhibition of MEK and dual PI 3k/mTOR diminishes viability and inhibits tumor growth of canine melanoma underscoring its utility as a preclinical model for human mucosal melanoma. Pigment Cell Melanoma Res 29(6):643-655. https://doi.org/10.1111/Pcmr.12512

115. Starkey M et al (2018) Metastasis-associated microRNA expression in canine uveal melanoma. Vet Comp Oncol 16(1):81-89. https://doi.org/10.1111/Vco.12315

116. Hodi FS (2010) Improved survival with ipilimumab in patients with metastatic melanoma. N Engl J Med 363(8):711-723. https ://doi.org/10.1056/Nejmoa1003466

117. Tagawa $\mathrm{M}$ et al (2016) Evaluation of costimulatory molecules in peripheral blood lymphocytes of canine patients with histiocytic sarcoma. PloS ONE 11(2):E0150030. https://doi.org/10.1371/ Journal.Pone.0150030

118. Maekawa $N$ et al (2017) A canine chimeric monoclonal antibody targeting PD-L1 and its clinical efficacy in canine oral malignant melanoma or undifferentiated sarcoma. Sci Rep 7(1):8951. https ://doi.org/10.1038/S41598-017-09444-2

119. Balachandran VP, DeMatteo RP (2014) Gist tumors: who should get imatinib and for how long? Adv Surg 48(1):165. https://doi. org/10.1016/J.Yasu.2014.05.014

120. Irie $M$ et al (2015) Imatinib mesylate treatment in a dog with gastrointestinal stromal tumors with a c-Kit mutation. J Vet Med Sci 77(11):1535-1539. https://doi.org/10.1292/Jvms.15-0096

121. Isotani $\mathrm{M}$ et al (2008) Effect of tyrosine kinase inhibition by imatinib mesylate on mast cell tumors in dogs. J Vet Int Med 22(4):985-988. https://doi.org/10.1111/J.1939-1676.2008.00132 .X

122. Macewen EG (1990) Spontaneous tumors in dogs and cats: models for the study of cancer biology and treatment. Cancer Metastasis Rev 9(2):125-136. https://doi.org/10.1007/Bf00046339
123. Wypij JM (2013) A naturally occurring feline model of head and neck squamous cell carcinoma. Pathol Res Int. https://doi. org/10.1155/2013/502197

124. Genden EM et al (2003) Neck disease and distant metastases. Oral Oncol 39(3):207-212. https://doi.org/10.1016/S1368 $-8375(02) 00049-0$

125. Anderson RL et al (2018) A framework for the development of effective anti-metastatic agents. Nat Rev Clin Oncol. https://doi. org/10.1038/S41571-018-0134-8

126. Botham RC et al (2016) Small-molecule procaspase-3 activation sensitizes cancer to treatment with diverse chemotherapeutics. ACS Cent Sci 2(8):545-559. https://doi.org/10.1021/Acscentsci $.6 \mathrm{~b} 00165$

127. Ta HT et al (2009) Osteosarcoma treatment: state of the art. Cancer Metastasis Rev 28(1-2):247-263. https://doi.org/10.1007/ S10555-009-9186-7

128. Selmic L (2014) Comparison of carboplatin and doxorubicinbased chemotherapy protocols in $470 \mathrm{dogs}$ after amputation for treatment of appendicular osteosarcoma. J Vet Intern Med 28(2):554-563. https://doi.org/10.1111/Jvim.12313

129. Macewen EG et al (1989) Therapy for osteosarcoma in dogs with intravenous injection of liposome-encapsulated muramyl tripeptide. Oxford University Press, Oxford. https://doi.org/10.1093/ Jnci/81.12.935

130. Kager L, Pötschger U, Bielack AS (2010) Review of mifamurtide in the treatment of patients with osteosarcoma. Therap Clin Risk Manag 6:279. https://doi.org/10.2147/Tcrm.S5688

131. Kleinerman ES et al (1992) Phase II study of liposomal muramyl tripeptide in osteosarcoma: the cytokine cascade and monocyte activation following administration. J Clin Oncol 10(8):1310 1316. https://doi.org/10.1200/Jco.1992.10.8.1310

132. Mason $\mathrm{N}$ et al (2016) Immunotherapy with a Her2 targeted listeria induces Her2-specific immunity and demonstrates potential therapeutic effects in a phase I trial in canine osteosarcoma. Clin Cancer Res. https://doi.org/10.1158/1078-0432.Ccr-16-0088

Publisher's Note Springer Nature remains neutral with regard to jurisdictional claims in published maps and institutional affiliations. 